\title{
Serum Vitamin D levels are associated with increased COVID-19 severity and mortality independent of whole-body and visceral \\ adiposity
}

Pablo Esteban Vanegas-Cedillo ${ }^{1,2^{*}}$, Omar Yaxmehen Bello-Chavolla ${ }^{1,3^{*}}$, Natalia RamírezPedraza $^{4}$, Bethsabel Rodríguez Encinas ${ }^{2}$, Carolina Isabel Pérez Carrión ${ }^{2}$, María Isabel Jasso-Ávila², Jorge Carlos Valladares-García², Diana Hernández-Juárez² ${ }^{2}$ Arsenio VargasVázquez, MD ${ }^{1,4}$, Neftali Eduardo Antonio-Villa ${ }^{1,4}$, Monica Chapa-lbarguengoitia ${ }^{5}$, Alfredo Ponce de Leon ${ }^{6}$, José Sifuentes-Osornio ${ }^{7,8}$ Carlos A. Aguilar-Salinas ${ }^{1,8,9}$, Roopa Mehta ${ }^{1,2 *}$

\section{*Both authors contributed equally to the drafting of this manuscript}

${ }^{1}$ Unidad de Investigación de Enfermedades Metabólicas, Instituto Nacional de Ciencias Médicas y Nutrición Salvador Zubirán (INCMNSZ). ²Department of Endocrinology and Metabolism, INCMNSZ, ${ }^{3}$ Research Division, Instituto Nacional de Geriatría. ${ }^{4} \mathrm{MD} / \mathrm{PhD}$ (PECEM) program, Faculty of Medicine, National Autonomous University of Mexico. ${ }^{5}$ Department of Radiology, INCMNSZ, ${ }^{6}$ Department of Infectious Diseases, INCMNSZ,

${ }^{7}$ Internal Medicine Division, INCMNSZ ${ }^{8}$ Instituto Tecnologico y de Estudios Superiores de Monterrey Tec Salud, ${ }^{9}$ Division of Nutrition, INCMNSZ.

Instituto Nacional de Ciencias Medicas y Nutricion Salvador Zubiran

${ }^{*}$ Correspondence: Roopa Mehta

Unidad de Investigación de Enfermedades Metabólicas, Instituto Nacional de Ciencias Médicas y Nutrición Salvador Zubirán/ Department of Endocrinology and Metabolism, Instituto Nacional de Ciencias Médicas y Nutrición Salvador Zubirán.

Tel +52 (55), 548709 00, 2405. Email: roopamehta@yahoo.com

3,105 text words; 38 references; 4 tables; 3 figures.

Running headline: Vitamin D, adverse COVID-19 outcomes and adiposity 


\section{ABSTRACT (229 WORDS)}

INTRODUCTION: Coronavirus disease (COVID-19) is a global pandemic. Vitamin D deficiency has been associated with susceptibility to infectious disease. In this study, the association between COVID-19 outcomes and vitamin D levels in patients attending a COVID-19 reference center in Mexico City are examined.

METHODS: Consecutive patients with confirmed COVID-19 were evaluated. All patients underwent clinical evaluation and follow-up, laboratory measurements and a thoracic computerized tomography, including the measurement of epicardial fat thickness. Low vitamin D was defined as levels $<20 \mathrm{ng} / \mathrm{mL}(<50 \mathrm{nmol} / \mathrm{L})$ and deficient Vitamin $D$ as a level $\leq 12 \mathrm{ng} / \mathrm{mL}(<30 \mathrm{nmol} / \mathrm{L})$

RESULTS: Of the 551 patients included, low vitamin D levels were present in $45.6 \%$ and deficient levels in $10.9 \%$. Deficient Vitamin D levels were associated with mortality (HR $2.11,95 \% \mathrm{Cl} 1.24-3.58, \mathrm{p}=0.006)$ but not with critical COVID-19, adjusted for age, sex, bodymass index and epicardial fat. Using model-based causal mediation analyses the increased risk of COVID-19 mortality conferred by low vitamin D levels was partly mediated by its effect on D-dimer and cardiac ultrasensitive troponins. Notably, increased risk of COVID-19 mortality conferred by low vitamin D levels was independent of BMI and epicardial fat.

CONCLUSION: Vitamin D deficiency $(\leq 12 \mathrm{ng} / \mathrm{mL}$ or $<30 \mathrm{nmol} / \mathrm{L})$, is independently associated with COVID-19 mortality after adjustment for visceral fat (epicardial fat thickness). Low vitamin D may contribute to a pro-inflammatory and pro-thrombotic state, increasing the risk for adverse COVID-19 outcomes.

Keywords: Vitamin D, COVID-19, SARS-CoV-2, Adiposity, Severe disease 


\section{INTRODUCTION}

Coronavirus Disease (COVID-19), caused by the novel coronavirus severe acute respiratory syndrome coronavirus 2 (SARS-CoV-2), has caused significant burden in healthcare systems world-wide. In Mexico, COVID-19 has caused a large number of deaths, primarily due to the large prevalence of cardio-metabolic diseases linked to adverse outcomes and additionally due to the impact of socio-demographic factors which impact healthcare access and quality of care across Mexico(1-4). SARS-CoV-2 spreads primarily by close contact with respiratory droplets from infected individuals and contaminated surfaces $(5,6)$. SARSCoV-2 infects cells using the angiotensin converting enzyme-2 (ACE-2) receptor; infection can produce an interstitial pneumonia that may progress to acute respiratory distress syndrome (ARDS) and death(7,8). COVID-19 severity has been shown to be modified by the presence of cardio-metabolic comorbidities as well as inflammatory markers which may reflect vascular or respiratory deterioration(9-12).

Vitamin D is a steroid hormone involved in essential physiological roles including preserving bone integrity, immunomodulation by stimulating innate immunity and tempering adaptive immunity, infectious disease prevention and cardiovascular health $(13,14)$. It also acts on the renin angiotensin aldosterone (RAAS) system, inhibiting the angiotensin converting enzyme $(A C E(7))$. Several factors are known to influence vitamin D levels; lower levels are associated with ethnicity, variation in sun exposure due to higher latitudes, season, time of day, clothing, sunscreen use and skin pigmentation, age, lower sun exposure, obesity and chronic illnesses(15). Low levels of vitamin D have been associated with increased susceptibility to infectious disease, particularly respiratory tract infections. Several studies have explored the relationship between COVID-19 and vitamin D levels(16,17); however, concerns regarding residual confounding and the lack of mechanistic interpretations for the association of low Vitamin D levels with adverse COVID-19 outcomes requires further 
studies. Overall, pooled evidence suggests that high Vitamin D levels have been associated with reduced risk of adverse COVID-19 outcomes, which may suggest a beneficial role for Vitamin D in COVID-19(18). Nevertheless, evidence from randomized controlled trials have not shown benefit from Vitamin D supplementation in COVID-19 or other infections due to the high heterogeneity across studies and its systematic use requires further evaluation(19,20).

The presence of obesity results in decreased bioavailability of vitamin $D$, which is probably related to sequestration into adipose tissue. Furthermore, higher visceral fat content has been shown to be related to a higher incidence of vitamin D deficiency $(21,22)$. Obesity and ethnicity are important risk factors for severe disease and are also known to modulate vitamin $\mathrm{D}$ levels. This may be particularly relevant in Mexico, where high rates of diabetes and obesity have been associated with an increased risk of severe COVID-19(9). Here, we evaluated the association between COVID-19 outcomes and Vitamin D levels in patients attending a COVID-19 reference center in Mexico City. We aimed to identify determinants of Vitamin D levels in COVID-19 patients and develop causal-mediation models to propose mechanisms by which Vitamin D may lead to increased COVID-19 mortality.

\section{METHODS}

\section{Study population}

This study included consecutive patients evaluated at the Instituto Nacional de Ciencias Médicas y Nutrición Salvador Zubirán (INCMNSZ), a COVID-19 reference center in Mexico City between 17th March and 31st May 2020 with complete vitamin D measurements at admission(10). Subjects were initially assessed at triage and required either ambulatory or in-hospital care for COVID-19 (confirmed with computerized tomography (CT) and/or via RT-qPCR test from nasopharyngeal swabs. At the time of this writing, the INCMNSZ was a reference center for COVID-19 patients, which attended primarily severe and critical cases 
of COVID-19 from Mexico City. All patients had moderate to severe disease as defined by National Institute of Health criteria (Moderate IIIness: Evidence of lower respiratory disease during clinical assessment or imaging and who have saturation of oxygen $\left(\mathrm{SpO}_{2}\right) \geq 94 \%$ on air. Severe IIIness: $\mathrm{SpO}_{2}<94 \%$ on air, a ratio of arterial partial pressure of oxygen to fraction of inspired oxygen $\left(\mathrm{PaO}_{2} / \mathrm{FiO}_{2}\right)<300 \mathrm{~mm} \mathrm{Hg}$, respiratory frequency $>30$ breaths/min, or lung infiltrates $>50 \%$ ). Subjects underwent a chest $\mathrm{CT}$, and a radiologist determined the degree of pulmonary parenchymal disease and assessed epicardial fat thickness as a proxy for visceral fat. In addition, a medical history, anthropometric measurements, and laboratory tests were obtained, including 25 hydroxy-vitamin D. The electronic files of each patient were reviewed to document the outcomes during hospitalization. All proceedings were approved by the research and ethics committee of the INCMNZ (Ref 3383) and informed consent was waived due to the nature of the study.

\section{Laboratory and clinical measurements}

Clinical variables and laboratory measures were obtained the time of initial evaluation. Physical examination included: weight, height, body mass index (BMI, calculated as weight in kilograms divided by squared height in meters), pulse oximeter saturation (SpO2), respiratory rate $(R R)$, temperature and arterial blood pressure (BP). Laboratory measurements included: full blood count and chemistry panel including liver function tests, C-reactive protein (CRP), fibrinogen, D-dimer, ferritin, troponin I (TPNI), erythrocyte sedimentation rate (ESR) and procalcitonin levels. The blood samples were processed in the central laboratory of the Instituto Nacional de Ciencias Médicas y Nutrición Salvador Zubirán, Vitamin D (25-hydroxivitamin D) was measured by chemiluminescence using the Abbott Architect I2000 equipment. Low levels of vitamin D were defined as $<20 \mathrm{ng} / \mathrm{mL}(<50$ $\mathrm{nmol} / \mathrm{L})$ and deficient as a levels $<12 \mathrm{ng} / \mathrm{mL}(<30 \mathrm{nmol} / \mathrm{L})(6-9)$. 
All patients underwent unenhanced CT scans including low-dose CT and two ultra-low-dose CT protocols with commonly reported imaging features of COVID-19 pneumonia. The thoracic CT was performed using a 64-slice scanner (GE MEDICAL SYSTEMS Revolution EVO). Epicardial adipose tissue (EAT) thickness was measured at 3 points (right atrioventricular fossa, left atrioventricular fossa, and anterior interventricular fossa) in the reformatted 4-chamber view using the multiplanar reconstruction (MPR) tool on the workstation(23-26). The maximum thickness of the EAT was determined from the surface of the myocardium to the pericardium (measured perpendicular to the pericardium). The measurements were made on 2 different occasions, obtaining a total of 6 measurements; the average of them was used for all statistical analyses. Pericardial adipose tissue (PAT) was quantified with the volume measurement tool with the Carestream system of the workstation. The thickness of the thoracic subcutaneous adipose tissue (TscAT) was measured from the anterior border of the sternum to the skin, at the level of the mitral valve in the axial plane of the tomography. The 80th gender-specific percentile of EAT thickness was obtained and used as the threshold to define increased EAT thickness. In addition, chest CT findings were recorded and used to evaluate severity of COVID infection(25).

COVID-19 outcomes

Outcomes included mortality and critical disease (defined as the combination of mortality and need for mechanical ventilation /intubation). For time-to-event analyses, time from selfreported symptom onset prior to evaluation until last follow-up (censoring) or death, whichever occurred first was estimated.

\section{Statistical analyses}

Cases with low and deficient vitamin D levels were analyzed using Student's t-test or MannWhitney $U$ according to the variable distribution (parametric or non-parametric) for continuous variables. The chi-squared test was applied for categorical variables. 
Logarithmic, squared root and cubic root transformations were carried out to ensure variable symmetry prior to modeling. Missing data on predictors other than Vitamin D were multiply imputed using the mice $\mathrm{R}$ package under the assumption of data missing completely at random and combined using Rubin's rules. All statistical analyses were conducted using $R$ software version 4.0.2.

\section{Predictors of vitamin D levels}

Linear regression analyses were fitted to identify predictors of log-transformed vitamin D levels in patients with COVID-19, and model selection was carried out using minimization of the Bayesian Information Criterion (BIC). Logistic regression models were also fitted using a dummy variable which defined low and deficient vitamin $D$ to identify predictors for these categories and again model selection was conducted using BIC. Finally, model diagnostics for linear regression were conducted using residual analyses and the Hosmer-Lemeshow test for logistic regression analyses.

\section{Prediction of mortality and severe COVID-19}

Cox proportional risk regression analyses was used to investigate the association of vitamin

D with mortality related to COVID-19. Univariate models and fully adjusted models were generated which included the following covariates: age, gender, BMI, C-reactive protein, Ddimer, ultrasensitive cardiac troponin, epicardial fat, T2D, CKD and oxygen saturation levels. An interaction effect was explored with BMI or BMI categories to rule out the differential impact of vitamin D adjusted for BMI. Model diagnostics were done using Schoenfeld residuals. Results are presented with Hazard Ratios (HR) and its corresponding 95\% confidence intervals. Finally, the association of vitamin D with requirement for mechanical ventilation or the composite of critical COVID-19 was explored using logistic regression analyses adjusted for the covariates. Results are presented with Odds Ratios (OR) and its corresponding $95 \%$ confidence intervals. 
medRxiv preprint doi: https://doi.org/10.1101/2021.03.12.21253490; this version posted December 29, 2021. The copyright holder for this preprint (which was not certified by peer review) is the author/funder, who has granted medRxiv a license to display the preprint in perpetuity.

It is made available under a CC-BY-NC-ND 4.0 International license .

\section{Causal mediation models}

Finally, to explore whether variables which are influenced by Vitamin D levels may act as a mediator of the risk conferred by Vitamin D on COVID-19 severity, model-based causal mediation analyses were developed: D-dimer and ultrasensitive cardiac troponins were proposed as mediators of the effect of Vitamin D on COVID-19 mortality. All mediation analyses were performed using the mediation $\mathrm{R}$ package; to permit inference to obtain a 95\% confidence interval using bias-corrected accelerated non-parametric bootstrap. To demonstrate the sequential ignorability assumption, a sensitivity analysis was run to demonstrate residual confounding by varying the correlation between the residuals of both the outcome and the moderator models. Statistical analyses were performed using $\mathrm{R}$ software version 4.0.3. A p value $<0.05$ was considered statistically significant

\section{RESULTS}

\section{Study population}

This study included 551 patients with confirmed COVID-19 (with compatible computerized tomography findings and/or positive RT-qPCR test from nasopharyngeal swabs) and vitamin D measurements. The mean age of participants was $51.92 \pm 13.74$ years, with a male predominance $(n=355,64.4 \%)$, and a mean BMI of $30.05 \pm 5.72$. Median follow-up was 15.0 days (IQR 10.0, 20.0) and 445 patients required hospitalization (81.1\%). Overall, 93 patients received invasive mechanical ventilation (16.88\%) and 116 in-hospital deaths $(21.1 \%)$ were recorded. Type 2 diabetes (T2D) was present in 146 patients (26.9\%), 219 patients had obesity (42.7\%) and 217 were overweight (42.4\%). Mean vitamin D levels were $21.78 \pm 9.01$ and vitamin D levels below $20 \mathrm{ng} / \mathrm{mL}$ were present in 251 subjects (45.6\%) (Table 1). Extremely low vitamin D levels $(\leq 12 \mathrm{ng} / \mathrm{mL})$ were observed in 59 patients $(10.7 \%)$ (Table 1 supplementary material).

Determinants of Vitamin D levels amongst patients with COVID-19 
The pathophysiological adaptations to COVID-19 may be predictive of low vitamin D levels. To this end, determinants of low vitamin D in COVID-19 were sought in an attempt to develop a mechanistic explanatory model for this relationship. Subjects with low vitamin D levels (<20mmg/dl) were more likely to be female, have type 2 diabetes, higher HbA1c, D-dimer and ferritin levels and lower oxygen saturation, albumin and C-reactive protein. Using linear regression, a lower log-transformed vitamin D level was independently associated with female gender, higher log-transformed ultrasensitive cardiac troponin, higher logtransformed D-dimer, higher log-transformed epicardial fat area, and lower C-reactive protein levels (Table 2). When exploring a model to detect low vitamin D levels, there was a significantly higher odds for log-transformed D-dimer levels (OR 1.31, 95\%Cl 1.06, 1.63); lower odds were associated with male gender (OR $0.45,95 \% \mathrm{Cl} 0.31,0.65)$, higher oxygen saturation levels $(\mathrm{OR} 0.98,95 \% \mathrm{Cl} 0.97,0.99)$ and higher C-reactive protein values (OR $0.75,95 \% \mathrm{Cl} 0.61,0.92)$, adjusted for age, and log-transformed epicardial fat. There was no association between days from symptom onset and vitamin D levels at admission.

\section{Vitamin D levels and COVID-19 mortality}

Overall, vitamin D levels were significantly lower when comparing non-fatal to fatal COVID19 cases $(22.41 \pm 9.34$ vs. $19.44 \pm 67.19, p<0.001)$. When assessing risk related to the association between mortality and vitamin D levels using Cox regression, a 1-unit increase in vitamin D levels was associated with a decreased risk of COVID-19 mortality. Interestingly, when stratifying cases according to gender, the difference in vitamin D levels between fatal and non-fatal cases was greater in women compared to men and lower in cases with obesity (Figure 1). When the mortality models were adjusted for age, gender, $\mathrm{BMI}$, and C-reactive protein, CKD and T2D the observed association between vitamin D levels and a decrease in COVID-19 mortality persisted (Table 3). There was no significant interaction with BMI, (as a continuous variable or categorized) in normal weight, overweight 
and obese with vitamin D levels. Using post-estimation simulation to predict risk associated with changes in vitamin D levels using the simPH R package, there was a steady decrease in risk attributable to increasing vitamin $D$ concentrations using vitamin $D<20 \mathrm{ng} / \mathrm{mL}$ and $\leq 12 \mathrm{ng} / \mathrm{mL}$ as thresholds (Figure 2).

Vitamin D and critical COVID-19

When assessing the impact of vitamin $D$ on the risk of invasive mechanical ventilation there was no significant association even after adjustment for age, gender, BMI, C-reactive protein, CKD or T2D status (OR 0.986, 95\%Cl 0.957, 1.015, p=0.366). However, when assessing the composite of critical COVID-19 using logistic regression models, lower vitamin D levels were associated with critical COVID-19 (OR 0.97, 95\%Cl 0.94, 0.99, p=0.042, adjusting by age, gender, BMI, C-reactive protein, D-dimer, CKD, SpO2 or T2D status).

\section{Causal mediation models}

Finally, model-based causal mediation models were developed to assess whether the effect of vitamin $\mathrm{D}(\mathrm{E})$ on increased mortality risk $(\mathrm{Y})$ was mediated through changes in variables identified in Table 2 (M), adjusted for age, gender, BMI and epicardial fat. The direct effect of vitamin $D$ on increased mortality risk was significant $\left(\Delta_{\mathrm{E} \rightarrow \mathrm{Y}}-0.144,95 \% \mathrm{Cl}-0.069,-0.010\right)$ and the indirect effect of vitamin $D$, mediated by increase $D$-dimer levels $\left(\Delta_{E \rightarrow M Y}-0.035\right.$, $95 \% \mathrm{Cl}-0.164,-0.010)$, represented $19.3 \%(95 \% \mathrm{Cl} 9.5,77.0 \%)$ of the overall association of vitamin $D$ on mortality. A similar scenario was observed for cardiac troponins, whereby both the direct effect of vitamin $D$ on mortality $\left(\Delta_{E \rightarrow Y}-0.133,95 \% \mathrm{Cl}-0.150,-0.020\right)$ and the indirect effect mediated by ultrasensitive cardiac troponins $\left(\Delta_{\mathrm{E} \rightarrow \mathrm{MY}}-0.047,95 \% \mathrm{Cl}-0.085\right.$, 0.020), were significant and represented $26.2 \%(95 \% \mathrm{Cl} 14.9,73.0 \%)$ of the overall effect of vitamin D on mortality. Notably, there were no significant causal mediation models for either BMI or epicardial fat, here there was only a direct effect on mortality, independent of vitamin D levels. 


\section{DISCUSSION}

In this study, the association between vitamin D levels and severity of COVID-19 was explored in a Mexican population. Deficient levels of vitamin D (deficiency) showed a clear association with mortality, even after adjusting for confounders, including epicardial fat as a proxy of visceral fat and BMI. A vitamin D level $<20 \mathrm{ng} / \mathrm{mL}(<50 \mathrm{nmol} / \mathrm{L})$, showed a strong negative predictive value, suggesting that when levels are adequate, the probability of mortality is low. Furthermore, the increased risk of mortality from COVID-19 was partly mediated by the effect of vitamin D on markers of disease severity, such as D-dimer and ultrasensitive cardiac troponins, independent of BMI and epicardial fat (these showed effects on COVID-19 mortality independent of vitamin D levels). This suggests that vitamin D may be a marker of an impaired response to infection within the pulmonary epithelium, most notably in those with severe deficiency(27).

Several studies have explored the relationship between COVID-19 and vitamin levels $(18,20,27,28)$. These include those examining vitamin $D$ levels and risk of infection and those examining an association with severity of COVID-19. Higher levels of IL-6 were observed in vitamin D deficiency suggesting a greater inflammatory response in these patients $(29,30)$. A recent systematic review and meta-analysis reported that vitamin $D$ deficiency was not associated with increased risk of infection, but severe cases presented with greater vitamin $\mathrm{D}$ deficiency compared with mild cases. Vitamin $\mathrm{D}$ deficiency has been associated to increased hospitalization and mortality risk from COVID-19(16,18). Physiological mechanisms by which vitamin D exerts a protective function include enhanced innate immunity including augmentation of physical barriers to infection and optimization of adaptive immunity(27). Vitamin D has also been proposed to exert a modulatory effect on the inflammatory response caused by COVID-19 by curbing adaptive immunity though inhibition og B cell proliferation, differentiation and production of antibodies and plays a role 
in regulation the $\mathrm{T}$ cell phenotype. Thus, there is a shift in the adaptive immune response from Th1 to a more regulatory Th2 response, characterized by an increase in expression of Th2 associated cytokines. This may attenuate the quantity of pro-inflammatory cytokines that are associated with severe infection(27). In addition, vitamin D induces ACE-2 expression, and suppresses the angiotensin-renin system, thus reducing levels of proinflammatory angiotensin II. Hence, vitamin D deficiency, could potentiate the cytokine storm perpetuating a pro-inflammatory state and worsening pulmonary outcomes $(28,29)$. Finally, thrombotic complications are common in such patients; vitamin D is also involved in the regulation of thrombotic pathways $(31,32)$. The mechanisms through which Vitamin $D$ may influence pro-thrombotic pathways is closely related to its anti-inflammatory properties, which reduce endothelial activation and oxidative stress(33). In our study, low vitamin D levels in COVID-19 patients were related to inflammatory, pro-thrombotic and metabolic markers of severity, confirming observations from previous studies.

Adverse COVID-19 outcomes have been linked to the ethnic origin of the population under study and its socio-economic characteristics; this has also been associated with the presence of vitamin D deficiency. Asians, African Americans, and ethnic minorities are at an increased risk of mortality from COVID-19(34). This may partly be due to a decrease in the production of vitamin D dependent on UV rays. This is related to the skin levels of melanin present in these populations and on the unequal distribution of poverty and cardiometabolic disease rates across such ethnicities and populations. This finding is relevant and may explain lower vitamin D levels and severity of COVID-19 in México in previous studies(3537). Previous reports in similar populations, including Hispanics, have shown higher risk of severe SARS-CoV-2 infection, compared to Caucasian population(38). This could be attributable to increased cardio-metabolic comorbidities in cases from Mexico, where vitamin D deficiency is more prevalent in type 2 diabetes and obesity primarily due to increased adiposity, as supported by our results(39). The relationship between vitamin D levels and 
sex may also underlie our finding of lower vitamin D levels in women, who have increased adiposity content compared to males(40). Low vitamin D levels may also occur in CKD, by reduced expression of 1-alpha hydroxylase; given a large, despite its influce on Vitamin D status, our study only included a reduced number of cases with CKD. Currently, routine vitamin D supplementation in hospitalized patients with COVID-19 is not recommended. A recent clinical trial study study showed that administration of a high dose of calcifediol or 25hydroxyvitamin D, did not reduce length of hospital stay in patients COVID-19 (20). Ideally, additional large randomized controlled trials are needed to properly assess this claim and whether vitamin D supplementation can significantly impact risk of severe COVID-19.

This study has certain strengths and limitations. It included a large sample of patients with heterogenous risk profiles in whom a variety of disease severity parameters were measured. In addition, a series of statistical tests were carried out to ensure minimal possibility of residual confounding. Nevertheless, some limitations must be acknowledged to properly interpret this study. First, a chemiluminescence immunoassay was used to assess vitamin D levels, this may lead to inconsistent results compared to other techniques including competitive binding protein - CBP, radioimmunoassay - RIA liquid chromatography - LC, UV detection with liquid chromatography and liquid chromatography mass spectrometry LCMS or tandem mass spectrometry. Since most patients were attended in the institution for the first time for COVID-19, historic vitamin D values were not available to assess the effect of vitamin D dynamics on infection risk or outcomes. Furthermore, given the disease course of COVID-19, severity profiles are highly heterogeneous even amongst hospitalized patients, which may influence vitamin D values based on varying severity; control for this factor using propensity score matching was carried out, however, there remains a possibility for residual confounding. Finally, since this is a secondary analysis, post-hoc sample size calculation was not performed, and negative results should be interpreted with caution. Notably, these results are from a COVID-19 reference center in Mexico City, this could reduce the 
representativeness of the findings primarily to severe and critical forms of COVID-19 from the central region of Mexico. Further evidence in other regions of Mexico to confirm the role of vitamin $D$ as a marker of disease severity and mortality in Mexicans with COVID-19 is needed.

\section{Conclusions}

Vitamin $D$ levels $\leq 12 \mathrm{ng} / \mathrm{ml}(30 \mathrm{nmol} / \mathrm{L})$ are independently associated with COVID-19 mortality, even after adjusting for confounders, including measures of visceral and total body fat. No association was confirmed between vitamin $D$ levels and the need for intubation. Vitamin D deficiency is more prevalent in women and patients with type 2 diabetes mellitus. Vitamin D supplementation may be considered in deficient patients, but evidence of benefit is required from double blind randomized controlled trials.

CONFLICT OF INTEREST/FINANCIAL DISCLOSURE: Nothing to disclose.

DATA AVAILABILITY: Data is available from the corresponding author upon reasonable request. Code for reproducibility of results available at: https://github.com/oyaxbell/covid metabolism

FUNDING: This research did not receive any specific grant from funding agencies in the public, commercial, or not-for-profit sectors.

\section{ACKNOWLEDGMENTS}

All authors approved the submitted version. All the authors would like to thank the staff of the Endocrinology and Metabolism Department for all their support. We are thankful to the study volunteers for all their work and support throughout the realization of the study. AVV, and NEAV are enrolled in the PECEM program at the Faculty of Medicine of UNAM; AVV and NEAV are supported by CONACyT. 
CONTRIBUTIONS: research idea and study design: RM, OYBC, CAAS; data acquisition: RM, PEVC, NRP, MAJA, CIPC, BRE, JCVG, CAAS; data analysis/interpretation: OYBC, RM, CAAS, NEAV, AVV; statistical analysis: OYBC, NEAV; manuscript drafting: RM, OYBC, NEAV, AVV, CAAS; supervision or mentorship: RM, CAAS, APL, JSO. Each author contributed important intellectual content during manuscript drafting or revision and accepts accountability for the overall work by ensuring that questions pertaining to the accuracy or integrity of any portion of the work are appropriately investigated and resolved.

\section{REFERENCES}

1. Antonio-Villa NE, Fernandez-Chirino L, Pisanty-Alatorre J, Mancilla-Galindo J, Kammar-García A, Vargas-Vázquez A, González-Díaz A, Fermín-Martínez CA, Márquez-Salinas A, Guerra EC, et al. Comprehensive evaluation of the impact of sociodemographic inequalities on adverse outcomes and excess mortality during the COVID-19 pandemic in Mexico City. Clin Infect Dis Off Publ Infect Dis Soc Am (2021)ciab577. doi: 10.1093/cid/ciab577

2. Bello-Chavolla OY, González-Díaz A, Antonio-Villa NE, Fermín-Martínez CA, Márquez-Salinas A, Vargas-Vázquez A, Bahena-López JP, García-Peña C, AguilarSalinas CA, Gutiérrez-Robledo LM. Unequal Impact of Structural Health Determinants and Comorbidity on COVID-19 Severity and Lethality in Older Mexican Adults: Considerations Beyond Chronological Aging. J Gerontol Ser A (2021) 76:e52-e59. doi: 10.1093/gerona/glaa163

3. Vargas-Vázquez A, Bello-Chavolla OY, Ortiz-Brizuela E, Campos-Muñoz A, Mehta R, Villanueva-Reza M, Bahena-López JP, Antonio-Villa NE, González-Lara MF, Ponce de León A, et al. Impact of undiagnosed type 2 diabetes and pre-diabetes on severity and 
mortality for SARS-CoV-2 infection. BMJ Open Diabetes Res Care (2021) 9:e002026. doi: 10.1136/bmjdrc-2020-002026

4. Antonio-Villa NE, Bello-Chavolla OY, Vargas-Vázquez A, Fermín-Martínez CA, Márquez-Salinas A, Pisanty-Alatorre J, Bahena-López JP. Assessing the Burden of Coronavirus Disease 2019 (COVID-19) Among Healthcare Workers in Mexico City: A Data-Driven Call to Action. Clin Infect Dis Off Publ Infect Dis Soc Am (2021) 73:e191e198. doi: 10.1093/cid/ciaa1487

5. Huang C, Wang Y, Li X, Ren L, Zhao J, Hu Y, Zhang L, Fan G, Xu J, Gu X, et al. Clinical features of patients infected with 2019 novel coronavirus in Wuhan, China. Lancet Lond Engl (2020) 395:497-506. doi: 10.1016/S0140-6736(20)30183-5

6. Cohen PA, Hall LE, John JN, Rapoport AB. The Early Natural History of SARS-CoV-2 Infection: Clinical Observations From an Urban, Ambulatory COVID-19 Clinic. Mayo Clin Proc (2020) 95:1124-1126. doi: 10.1016/j.mayocp.2020.04.010

7. Lu R, Zhao X, Li J, Niu P, Yang B, Wu H, Wang W, Song H, Huang B, Zhu N, et al. Genomic characterisation and epidemiology of 2019 novel coronavirus: implications for virus origins and receptor binding. Lancet Lond Engl (2020) 395:565-574. doi: 10.1016/S0140-6736(20)30251-8

8. Yang X, Yu Y, Xu J, Shu H, Xia J, Liu H, Wu Y, Zhang L, Yu Z, Fang M, et al. Clinical course and outcomes of critically ill patients with SARS-CoV-2 pneumonia in Wuhan, China: a single-centered, retrospective, observational study. Lancet Respir Med (2020) 8:475-481. doi: 10.1016/S2213-2600(20)30079-5

9. Bello-Chavolla OY, Bahena-López JP, Antonio-Villa NE, Vargas-Vázquez A, González-Díaz A, Márquez-Salinas A, Fermín-Martínez CA, Naveja JJ, Aguilar-Salinas CA. Predicting Mortality Due to SARS-CoV-2: A Mechanistic Score Relating Obesity and Diabetes to COVID-19 Outcomes in Mexico. J Clin Endocrinol Metab (2020) 105:2752-2761. doi: 10.1210/clinem/dgaa346 
10. Bello-Chavolla OY, Antonio-Villa NE, Ortiz-Brizuela E, Vargas-Vázquez A, GonzálezLara MF, de Leon AP, Sifuentes-Osornio J, Aguilar-Salinas CA. Validation and repurposing of the MSL-COVID-19 score for prediction of severe COVID-19 using simple clinical predictors in a triage setting: The Nutri-CoV score. PloS One (2020) 15:e0244051. doi: 10.1371/journal.pone.0244051

11. Ramírez-Aldana R, Gomez-Verjan JC, Bello-Chavolla OY, García-Peña C. Spatial epidemiological study of the distribution, clustering, and risk factors associated with early COVID-19 mortality in Mexico. PloS One (2021) 16:e0254884. doi: 10.1371/journal.pone.0254884

12. Sarengat R, Islam MS, Ardhi MS. Correlation of neutrophil-to-lymphocyte ratio and clinical outcome of acute thrombotic stroke in patients with COVID-19. Narra J (2021) 1: doi: 10.52225/narra.v1i3.50

13. Malek Mahdavi A. A brief review of interplay between vitamin D and angiotensinconverting enzyme 2: Implications for a potential treatment for COVID-19. Rev Med Virol (2020) 30:e2119. doi: 10.1002/rmv.2119

14. Tangpricha V, Pearce EN, Chen TC, Holick MF. Vitamin D insufficiency among freeliving healthy young adults. Am J Med (2002) 112:659-662. doi: 10.1016/s00029343(02)01091-4

15. Stoffers AJ, Weber DR, Levine MA. An Update on Vitamin D Deficiency in the twentyfirst century: nature and nurture. Curr Opin Endocrinol Diabetes Obes (2021) doi: 10.1097/MED.0000000000000691

16. Ma W, Nguyen LH, Yue Y, Ding M, Drew DA, Wang K, Merino J, Rich-Edwards JW, Sun Q, Camargo CA, et al. Associations between predicted vitamin D status, vitamin D intake, and risk of SARS-CoV-2 infection and Coronavirus Disease 2019 severity. Am J Clin Nutr (2021)nqab389. doi: 10.1093/ajcn/nqab389 
17. Mitchell F. Vitamin-D and COVID-19: do deficient risk a poorer outcome? Lancet Diabetes Endocrinol (2020) 8:570. doi: 10.1016/S2213-8587(20)30183-2

18. Hariyanto TI, Intan D, Hananto JE, Harapan H, Kurniawan A. Vitamin D supplementation and Covid-19 outcomes: A systematic review, meta-analysis and meta-regression. Rev Med Virol n/a:e2269. doi: 10.1002/rmv.2269

19. Jolliffe DA, Camargo CA, Sluyter JD, Aglipay M, Aloia JF, Ganmaa D, Bergman P, Bischoff-Ferrari HA, Borzutzky A, Damsgaard CT, et al. Vitamin D supplementation to prevent acute respiratory infections: a systematic review and meta-analysis of aggregate data from randomised controlled trials. Lancet Diabetes Endocrinol (2021) 9:276-292. doi: 10.1016/S2213-8587(21)00051-6

20. Murai IH, Fernandes AL, Sales LP, Pinto AJ, Goessler KF, Duran CSC, Silva CBR, Franco AS, Macedo MB, Dalmolin HHH, et al. Effect of a Single High Dose of Vitamin D3 on Hospital Length of Stay in Patients With Moderate to Severe COVID-19: A Randomized Clinical Trial. JAMA (2021) 325:1053-1060. doi: 10.1001/jama.2020.26848

21. Zhang M, Li P, Zhu Y, Chang H, Wang X, Liu W, Zhang Y, Huang G. Higher visceral fat area increases the risk of vitamin D insufficiency and deficiency in Chinese adults. Nutr Metab (2015) 12:50. doi: 10.1186/s12986-015-0046-x

22. Pascot A, Lemieux S, Lemieux I, Prud'homme D, Tremblay A, Bouchard C, Nadeau A, Couillard C, Tchernof A, Bergeron J, et al. Age-related increase in visceral adipose tissue and body fat and the metabolic risk profile of premenopausal women. Diabetes Care (1999) 22:1471-1478. doi: 10.2337/diacare.22.9.1471

23. Lu MT, Ersoy H, Whitmore AG, Lipton MJ, Rybicki FJ. Reformatted Four-Chamber and Short-Axis Views of the Heart Using Thin Section $(</=2 \mathrm{~mm})$ MDCT Images. Acad Radiol (2007) 14:1108-1112. doi: 10.1016/j.acra.2007.05.019 
24. Bertaso AG, Bertol D, Duncan BB, Foppa M. Epicardial fat: definition, measurements and systematic review of main outcomes. Arq Bras Cardiol (2013) 101:e18-28. doi: 10.5935/abc. 20130138

25. Mehta R, Bello-Chavolla OY, Mancillas-Adame L, Rodriguez-Flores M, Pedraza NR, Encinas BR, Carrión CIP, Ávila MIJ, García JCV, Vanegas-Cedillo PE, et al. Epicardial adipose tissue thickness is associated with increased severity and mortality related to SARS-CoV-2 infection. (2021). doi: 10.1101/2021.03.14.21253532

26. Wang T-D, Lee W-J, Shih F-Y, Huang C-H, Chang Y-C, Chen W-J, Lee Y-T, Chen MF. Relations of epicardial adipose tissue measured by multidetector computed tomography to components of the metabolic syndrome are region-specific and independent of anthropometric indexes and intraabdominal visceral fat. $J$ Clin Endocrinol Metab (2009) 94:662-669. doi: 10.1210/jc.2008-0834

27. Evans RM, Lippman SM. Shining Light on the COVID-19 Pandemic: A Vitamin D Receptor Checkpoint in Defense of Unregulated Wound Healing. Cell Metab (2020) 32:704-709. doi: 10.1016/j.cmet.2020.09.007

28. Bilezikian JP, Bikle D, Hewison M, Lazaretti-Castro M, Formenti AM, Gupta A, Madhavan MV, Nair N, Babalyan V, Hutchings $\mathrm{N}$, et al. MECHANISMS IN ENDOCRINOLOGY: Vitamin D and COVID-19. Eur J Endocrinol (2020) 183:R133R147. doi: 10.1530/EJE-20-0665

29. Baeke F, Takiishi T, Korf H, Gysemans C, Mathieu C. Vitamin D: modulator of the immune system. Curr Opin Pharmacol (2010) 10:482-496. doi: 10.1016/j.coph.2010.04.001

30. Jeffery LE, Burke F, Mura M, Zheng Y, Qureshi OS, Hewison M, Walker LSK, Lammas DA, Raza K, Sansom DM. 1,25-Dihydroxyvitamin D3 and IL-2 combine to inhibit T cell production of inflammatory cytokines and promote development of regulatory $\mathrm{T}$ cells 
expressing CTLA-4 and FoxP3. J Immunol Baltim Md 1950 (2009) 183:5458-5467. doi: 10.4049/jimmunol.0803217

31. Márquez-Salinas A, Fermín-Martínez CA, Antonio-Villa NE, Vargas-Vázquez A, Guerra EC, Campos-Muñoz A, Zavala-Romero L, Mehta R, Bahena-López JP, OrtizBrizuela E, et al. Adaptive Metabolic and Inflammatory Responses Identified Using Accelerated Aging Metrics Are Linked to Adverse Outcomes in Severe SARS-CoV-2 Infection. J Gerontol A Biol Sci Med Sci (2021) 76:e117-e126. doi: 10.1093/gerona/glab078

32. Salamanna F, Maglio M, Sartori M, Landini MP, Fini M. Vitamin D and Platelets: A Menacing Duo in COVID-19 and Potential Relation to Bone Remodeling. Int J Mol Sci (2021) 22:10010. doi: 10.3390/ijms221810010

33. Tao J, Lou F, Liu Y. The Role of Vitamin D in the Relationship Between Gender and Deep Vein Thrombosis Among Stroke Patients. Front Nutr (2021) 8:755883. doi: 10.3389/fnut.2021.755883

34. Acosta AM, Garg S, Pham H, Whitaker M, Anglin O, O’Halloran A, Milucky J, Patel K, Taylor C, Wortham J, et al. Racial and Ethnic Disparities in Rates of COVID-19Associated Hospitalization, Intensive Care Unit Admission, and In-Hospital Death in the United States From March 2020 to February 2021. JAMA Netw Open (2021) 4:e2130479. doi: 10.1001/jamanetworkopen.2021.30479

35. Parra-Ortega I, Alcara-Ramírez DG, Ronzon-Ronzon AA, Elías-García F, Mata-Chapol JA, Cervantes-Cote AD, López-Martínez B, Villasis-Keever MA, Zurita-Cruz JN. 25Hydroxyvitamin D level is associated with mortality in patients with critical COVID-19: a prospective observational study in Mexico City. Nutr Res Pract (2021) 15:S32-S40. doi: 10.4162/nrp.2021.15.S1.S32

36. Sánchez-Zuno GA, González-Estevez G, Matuz-Flores MG, Macedo-Ojeda G, Hernández-Bello J, Mora-Mora JC, Pérez-Guerrero EE, García-Chagollán M, Vega- 
Magaña N, Turrubiates-Hernández FJ, et al. Vitamin D Levels in COVID-19 Outpatients from Western Mexico: Clinical Correlation and Effect of Its Supplementation. J Clin Med (2021) 10:2378. doi: 10.3390/jcm10112378

37. Ramirez-Sandoval JC, Castillos-Ávalos VJ, Paz-Cortés A, Santillan-Ceron A, Hernandez-Jimenez S, Mehta R, Correa-Rotter R. Very Low Vitamin D Levels are a Strong Independent Predictor of Mortality in Hospitalized Patients with Severe COVID19. Arch Med Res (2021)S0188-4409(21)00198-3. doi: 10.1016/j.arcmed.2021.09.006

38. Pan D, Sze S, Minhas JS, Bangash MN, Pareek N, Divall P, Williams CM, Oggioni MR, Squire IB, Nellums LB, et al. The impact of ethnicity on clinical outcomes in COVID-19: A systematic review. EClinicalMedicine (2020) 23:100404. doi: 10.1016/j.eclinm.2020.100404

39. Abbas MA. Physiological functions of Vitamin D in adipose tissue. J Steroid Biochem Mol Biol (2017) 165:369-381. doi: 10.1016/j.jsbmb.2016.08.004

40. Muscogiuri G, Barrea L, Somma CD, Laudisio D, Salzano C, Pugliese G, de Alteriis G, Colao A, Savastano S. Sex Differences of Vitamin D Status across BMI Classes: An Observational Prospective Cohort Study. Nutrients (2019) 11:E3034. doi: $10.3390 /$ nu11123034 
medRxiv preprint doi: https://doi.org/10.1101/2021.03.12.21253490; this version posted December 29, 2021. The copyright holder for this preprint (which was not certified by peer review) is the author/funder, who has granted medRxiv a license to display the preprint in perpetuity.

It is made available under a CC-BY-NC-ND 4.0 International license .

\section{TABLES}

Table 1. Clinical characteristics, imaging findings and severity scores in patients with COVID-19, comparing cases with and without low vitamin D levels. Values are presented as mean ( \pm standard deviation) or median (inter-quartile range), where appropriate.

\begin{tabular}{|c|c|c|c|}
\hline & Vitamin D & Vitamin D & \\
\hline Parameter & $\begin{array}{c}{[>20 \mathrm{ng} / \mathrm{mL}]} \\
(n=300)\end{array}$ & $\begin{array}{c}{[\leq 20 \mathrm{ng} / \mathrm{mL}]} \\
(\mathrm{n}=251)\end{array}$ & P-value \\
\hline Age (years) & $53.0( \pm 14.92)$ & $51.0( \pm 12.60)$ & 0.088 \\
\hline Male Sex (\%) & $219(73)$ & $136(54.2)$ & $<0.001$ \\
\hline $\begin{array}{l}\text { Low-Socioeconomic Status } \\
\qquad(\%)\end{array}$ & $203(67.66)$ & $172(68.5)$ & 0.902 \\
\hline Critical outcome (\%) & $85(28.3)$ & $81(32.3)$ & 0.363 \\
\hline Intubation (\%) & $53(17.6)$ & $40(15.9)$ & 0.670 \\
\hline Mortality (\%) & $57(19)$ & $59(23.5)$ & 0.23 \\
\hline Arterial Hypertension (\%) & $83(27.94)$ & $89(35.9)$ & 0.058 \\
\hline Type 2 diabetes (\%) & $68(22.9)$ & $78(31.6)$ & 0.031 \\
\hline Time since diagnosis (years) & $9.8( \pm 7.8)$ & $9.20( \pm 7.5)$ & 0.831 \\
\hline Obesity (\%) & $118(39.9)$ & $111(44.9)$ & 0.269 \\
\hline Smoking status (\%) & $15(5.8)$ & $12(5.8)$ & 0.789 \\
\hline
\end{tabular}




\begin{tabular}{|c|c|c|c|}
\hline CKD (\%) & $6(2.0)$ & $12(4.9)$ & 0.111 \\
\hline CVD (\%) & $6(2.0)$ & $10(4.0)$ & 0.258 \\
\hline Cirrhosis (\%) & $0(0)$ & $3(1.21)$ & 0.186 \\
\hline BMI (kg/m2) & $29.83( \pm 4.9)$ & $30.3( \pm 6.6)$ & 0.343 \\
\hline Respiratory Rate (rpm) & $28.5( \pm 12.4)$ & $28.3( \pm 9.11)$ & 0.821 \\
\hline Heart Rate (bpm) & $102.3( \pm 18.2)$ & $101.9( \pm 18.5)$ & 0.771 \\
\hline $\begin{array}{l}\text { Systolic Arterial Pressure } \\
\qquad(\mathrm{mmHg})\end{array}$ & $120(110-131)$ & $123(110-135)$ & 0.264 \\
\hline $\begin{array}{l}\text { Diastolic Arterial Pressure } \\
\qquad(\mathrm{mmHg})\end{array}$ & $76(70-80)$ & $74(67-81)$ & 0.322 \\
\hline Oxygen saturation (\%) & $82.65( \pm 11.4)$ & $79.89( \pm 13.4)$ & 0.010 \\
\hline C-reactive protein & $14.9(9.0-23.2)$ & $13.6(6.4-21.8)$ & 0.052 \\
\hline Glucose levels (mg/dL) & $149.7( \pm 85.7)$ & $163.6( \pm 98.0)$ & 0.081 \\
\hline $\mathrm{HbA} 1 \mathrm{c}(\%)$ & $6.1(5.8-7.1)$ & $6.9(6.0-9.6)$ & 0.004 \\
\hline Triglycerides (mg/dL) & $149(114-192)$ & $140(110-179)$ & 0.291 \\
\hline HDL-C (mg/dL) & $32.7( \pm 15.3)$ & $33.3( \pm 10.7)$ & 0.911 \\
\hline LDL-C (mg/dL) & $95.9( \pm 57.4)$ & $75.1( \pm 34.7)$ & 0.282 \\
\hline Total Cholesterol (mg/dL) & $159.5( \pm 60.9)$ & $135.7( \pm 44.2)$ & 0.266 \\
\hline
\end{tabular}


medRxiv preprint doi: https://doi.org/10.1101/2021.03.12.21253490; this version posted December 29, 2021. The copyright holder for this preprint (which was not certified by peer review) is the author/funder, who has granted medRxiv a license to display the preprint in perpetuity. It is made available under a CC-BY-NC-ND 4.0 International license .

\begin{tabular}{|c|c|c|c|}
\hline Hemoglobin (\%) & $15.45(1.9)$ & $17.4(23.0)$ & 0.179 \\
\hline $\begin{array}{l}\text { Platelet Count }(1,000 \\
\text { cells/uL) }\end{array}$ & $231.0(90.9)$ & $236.5(103.8)$ & 0.509 \\
\hline $\begin{array}{l}\text { Lymphocytes }(1,000 \\
\text { cells/uL) }\end{array}$ & $8.9(4.4)$ & $9.2(4.9)$ & 0.529 \\
\hline Neutrophils (cells/uL) & $6435.0(4699.1)$ & $6336.8(5227.2)$ & 0.819 \\
\hline Serum Creatinine $(\mathrm{mg} / \mathrm{dL})$ & $0.9(0.8-1.2)$ & $0.9(0.7-1.2)$ & 0.645 \\
\hline Ferritin (mg/dL) & $\begin{array}{c}656.0(323.3- \\
1138.7)\end{array}$ & $553.3(284.7-959.7)$ & 0.062 \\
\hline D-Dimer (ng/mL) & $629(401-1049)$ & $821(454-1376)$ & 0.001 \\
\hline Protrombin time (seconds) & $\begin{array}{c}11.4(10.8- \\
12.4)\end{array}$ & $11.4(10.6-12.5)$ & 0.364 \\
\hline Fibrinogen (mg/dL) & $\begin{array}{c}697.0(556.5- \\
854.5)\end{array}$ & $672(482-789)$ & 0.014 \\
\hline BUN (mg/dL) & $18.1(11.6)$ & $20.7(17.7)$ & 0.054 \\
\hline AST (U/L) & $\begin{array}{c}42.6(30.5- \\
62.5)\end{array}$ & $41.4(30.1-64.7)$ & 0.679 \\
\hline $\operatorname{ALT}(\mathrm{U} / \mathrm{L})$ & $\begin{array}{c}35.9(23.7-55- \\
1)\end{array}$ & $33.50(23.8-58.2)$ & 0.632 \\
\hline
\end{tabular}


medRxiv preprint doi: https://doi.org/10.1101/2021.03.12.21253490; this version posted December 29, 2021. The copyright holder for this preprint (which was not certified by peer review) is the author/funder, who has granted medRxiv a license to display the preprint in perpetuity.

It is made available under a CC-BY-NC-ND 4.0 International license .

\begin{tabular}{|c|c|c|c|}
\hline Albumin (mg/dL) & $3.8(3.4-4.0)$ & $3.6(3.3-4.0)$ & 0.002 \\
\hline $\begin{array}{l}\text { Lactate dehydrogenase } \\
\qquad(\mathrm{U} / \mathrm{L})\end{array}$ & $361(291-466)$ & 374 (278.5-498.5) & 0.757 \\
\hline Creatinine Kinase (U/L) & $116(64-236)$ & $104.5(55-225.3)$ & 0.198 \\
\hline Procalcitonin (ng/mL) & $0.3(0.1-0.6)$ & $0.3(0.2-1.2)$ & 0.299 \\
\hline Symptoms (number) & $5(3-5)$ & $4(3-5)$ & 0.107 \\
\hline Comorbidities (number) & $1(0-1)$ & $1(0-2)$ & 0.001 \\
\hline Time hospitalized (days) & $6(3-10)$ & $6(3-10)$ & 0.995 \\
\hline \multicolumn{4}{|l|}{$\mathrm{CT}$ findings } \\
\hline Epicardial fat (\%) & $9.3(7.3-11.7)$ & $10(8.2-12.2)$ & 0.011 \\
\hline Pericardial fat (\%) & $185(61.7)$ & $145(57.8)$ & 0.407 \\
\hline Subthoracic fat (\%) & $15(10-21)$ & $17(12-24)$ & 0.010 \\
\hline Ground glass opacity (\%) & $297(99)$ & $248(98)$ & 0.710 \\
\hline Consolidations (\%) & $158(53.6)$ & $136(54.2)$ & 0.781 \\
\hline GGO + Consolidations (\%) & $158(53.6)$ & $136(54.2)$ & 0.721 \\
\hline $\begin{array}{l}\text { Lobules afected } \\
\qquad \begin{array}{l}1(\%) \\
2(\%) \\
3(\%)\end{array}\end{array}$ & $\begin{array}{l}34(11.3) \\
82(32.7) \\
132(52.6)\end{array}$ & $\begin{array}{c}34(11.3) \\
125(41.7) \\
140(46.6)\end{array}$ & 0.178 \\
\hline Hepatic steatosis (\%) & $99(33)$ & $90(35.9)$ & 0.539 \\
\hline
\end{tabular}


medRxiv preprint doi: https://doi.org/10.1101/2021.03.12.21253490; this version posted December 29, 2021. The copyright holder for this preprint (which was not certified by peer review) is the author/funder, who has granted medRxiv a license to display the preprint in perpetuity. It is made available under a CC-BY-NC-ND 4.0 International license .

Severity scores
NEWS (points)
$8(6-9)$
$8(7-9)$
0.733
QSOFA (points)
$1(1-1)$
$1(1-1)$
0.329
CURB-65 (points)
$1(0-2)$
$1(0-2)$
0.347

Abbreviations: NEWS, National Early Warning Score; QSOFA, Quick Sequential Organ

Failure Assessment Score; CURB-65, CURB-65 Score for Pneumonia Severity; GGO, Ground Glass Opacity; CT, Computed Tomography; CKD, Chronic Kidney Disease; CVD, Cardiovascular Disease; BUN, Blood Urea Nitrogen; BMI, Body mass index. 
medRxiv preprint doi: https://doi.org/10.1101/2021.03.12.21253490; this version posted December 29, 2021. The copyright holder for this preprint (which was not certified by peer review) is the author/funder, who has granted medRxiv a license to display the preprint in perpetuity.

It is made available under a CC-BY-NC-ND 4.0 International license .

Table 2. Multiple linear regression model to identify determinants of Vitamin $D$ levels in patients with COVID-19.

\begin{tabular}{|c|c|c|c|c|c|}
\hline Model & Parameter & $\begin{array}{c}\beta- \\
\text { coefficient }\end{array}$ & $95 \% \mathrm{Cl}$ & $\mathbf{t}$ & $\begin{array}{c}\text { P- } \\
\text { value }\end{array}$ \\
\hline \multirow{7}{*}{ Vitamin D } & Intercept & 3.515 & $3.177,3.853$ & 20.426 & $<0.001$ \\
\hline & Male Sex & 0.168 & $0.097,-0.238$ & 4.668 & $<0.001$ \\
\hline & $\begin{array}{c}\text { Ultrasensitive } \\
\text { troponin }\end{array}$ & -0.033 & $-0.063,-0.002$ & -2.124 & 0.034 \\
\hline & D-dimer & -0.060 & $-0.100,-0.020$ & -2.951 & 0.003 \\
\hline & $\begin{array}{c}\text { C-reactive } \\
\text { protein }\end{array}$ & 0.065 & $0.026,0.103$ & 3.265 & 0.001 \\
\hline & Epicardial fat & -0.126 & $-0.222,-0.031$ & -2.599 & 0.010 \\
\hline & Type 2 diabetes & -0.072 & $-0.147,0.004$ & -1.871 & 0.062 \\
\hline
\end{tabular}

Abbreviations: $95 \% \mathrm{Cl}, 95 \%$ Confidence intervals 
Table 3. Cox proportional risk regression models to predict mortality related to COVID-19 using Vitamin D levels adjusted for covariates. Model 1: Unadjusted, Model 2: Adjusted for age, gender, body-mass index (BMI) and C-reactive protein (CRP), Model 3: Model 2 adjusted for chronic kidney disease (CKD), epicardial fat and type 2 diabetes (T2D).

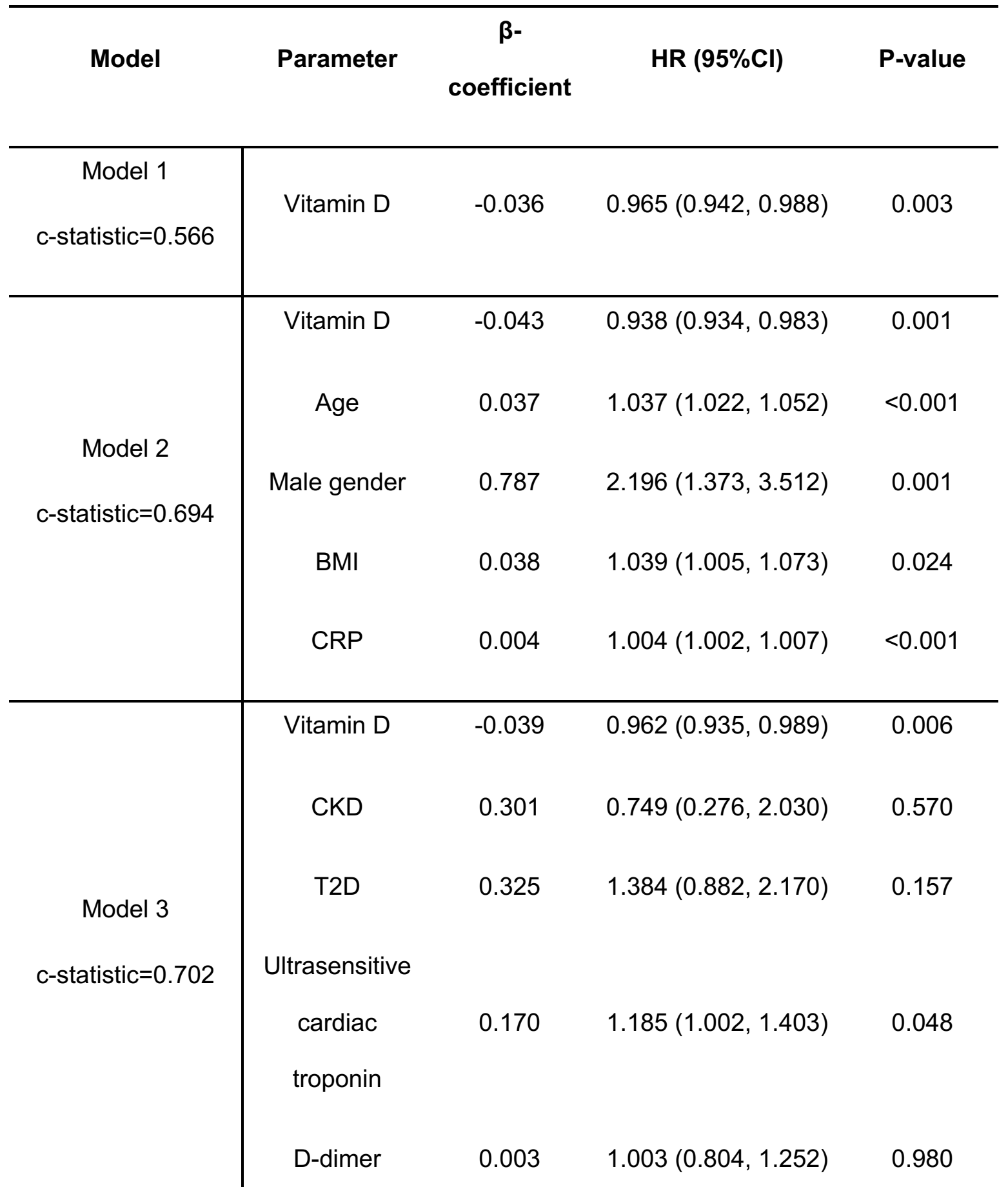


medRxiv preprint doi: https://doi.org/10.1101/2021.03.12.21253490; this version posted December 29, 2021. The copyright holder for this preprint (which was not certified by peer review) is the author/funder, who has granted medRxiv a license to display the preprint in perpetuity.

It is made available under a CC-BY-NC-ND 4.0 International license .

\begin{tabular}{l|llll}
\hline & $\begin{array}{c}\text { Oxygen } \\
\text { saturation }\end{array}$ & -0.026 & $0.975(0.960,0.990)$ & 0.001 \\
Epicardial fat & 0.669 & $1.952(0.501,7.607)$ & 0.335 \\
thickness & & & \\
\hline Abbreviations: CKD, Chronic Kidney Disease; BMI, Body mass index; CRP, C-reactive
\end{tabular}


Table 4: Causal mediation analyses predicting the effect of Vitamin D levels (E) mediated by elevated D-dimer, ultrasensitive cardiac troponins or low SpO2 (M) on severe COVID-19 and mortality $(\mathrm{Y})$, adjusted by gender, age, BMI and epicardial fat.

Abbreviations: ACME: average causal mediation effects; ADE: average direct effects; SpO2: Oxygen saturation levels.

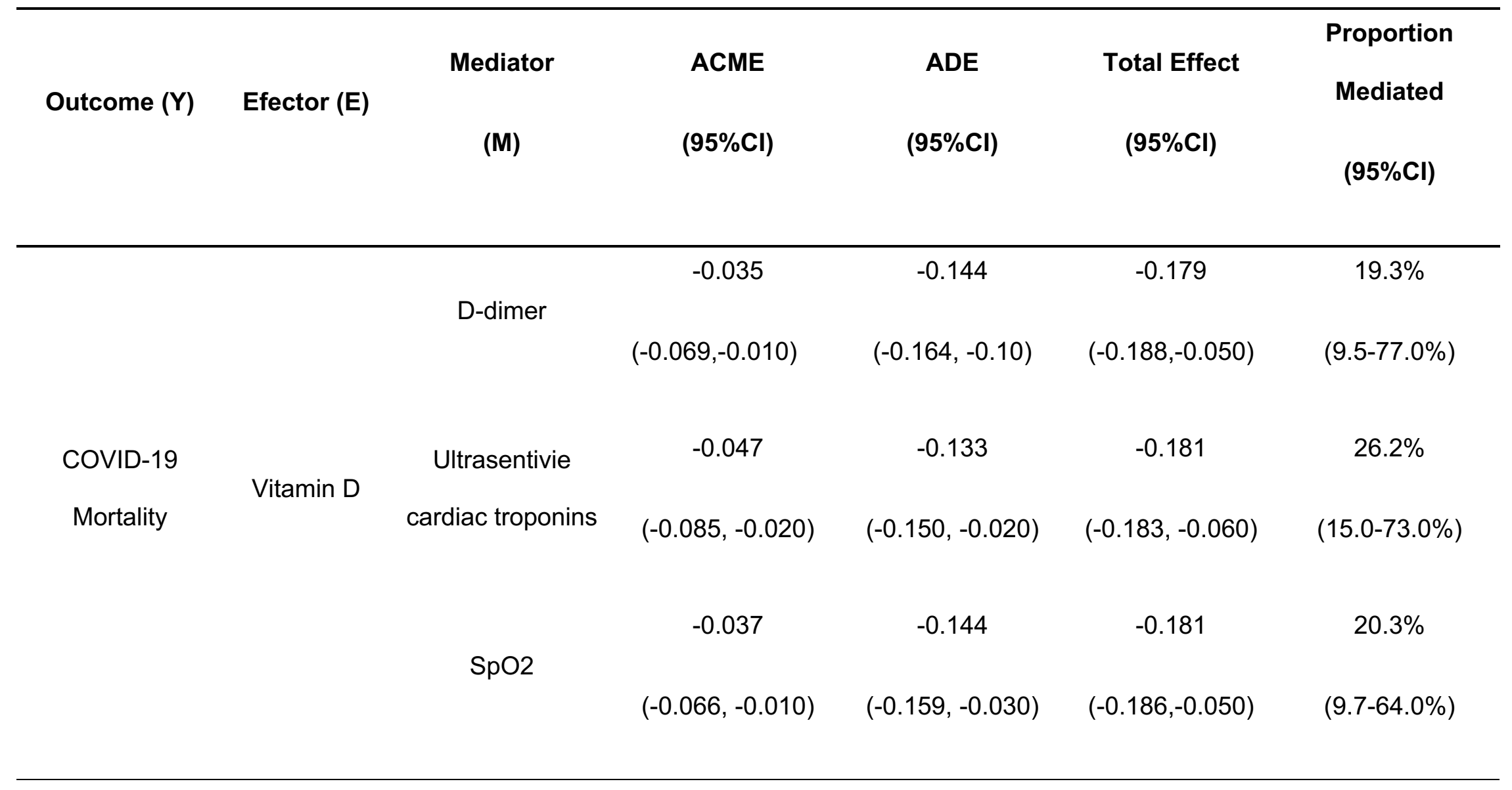




\section{FIGURE LEGENDS}
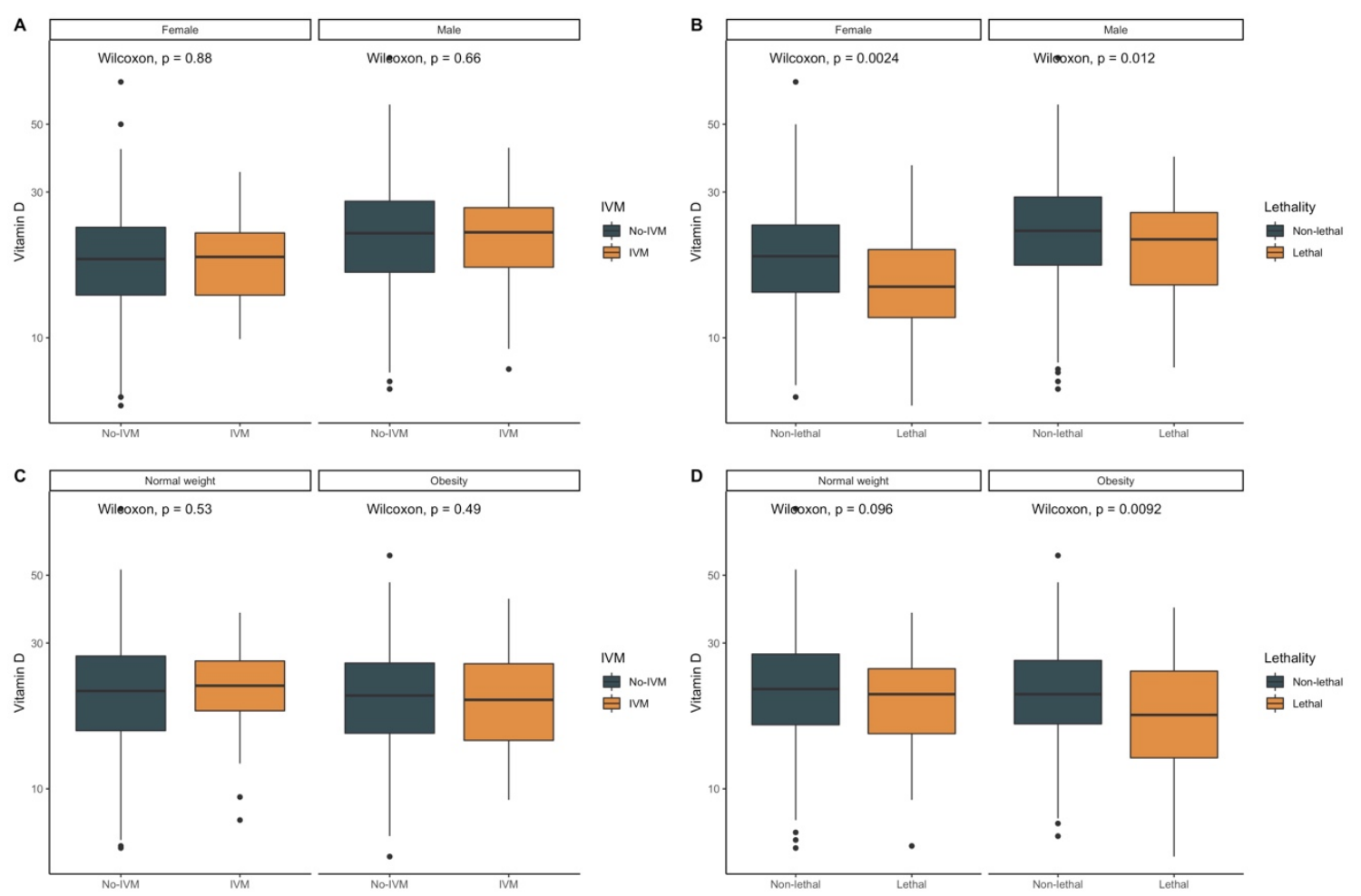

Figure 1. Boxplots comparing Vitamin D levels according to the need for invasive mechanical ventilation (IVM) or lethal COVID-19 stratified by gender (A-B) and by body-mass index categories (C-D). 

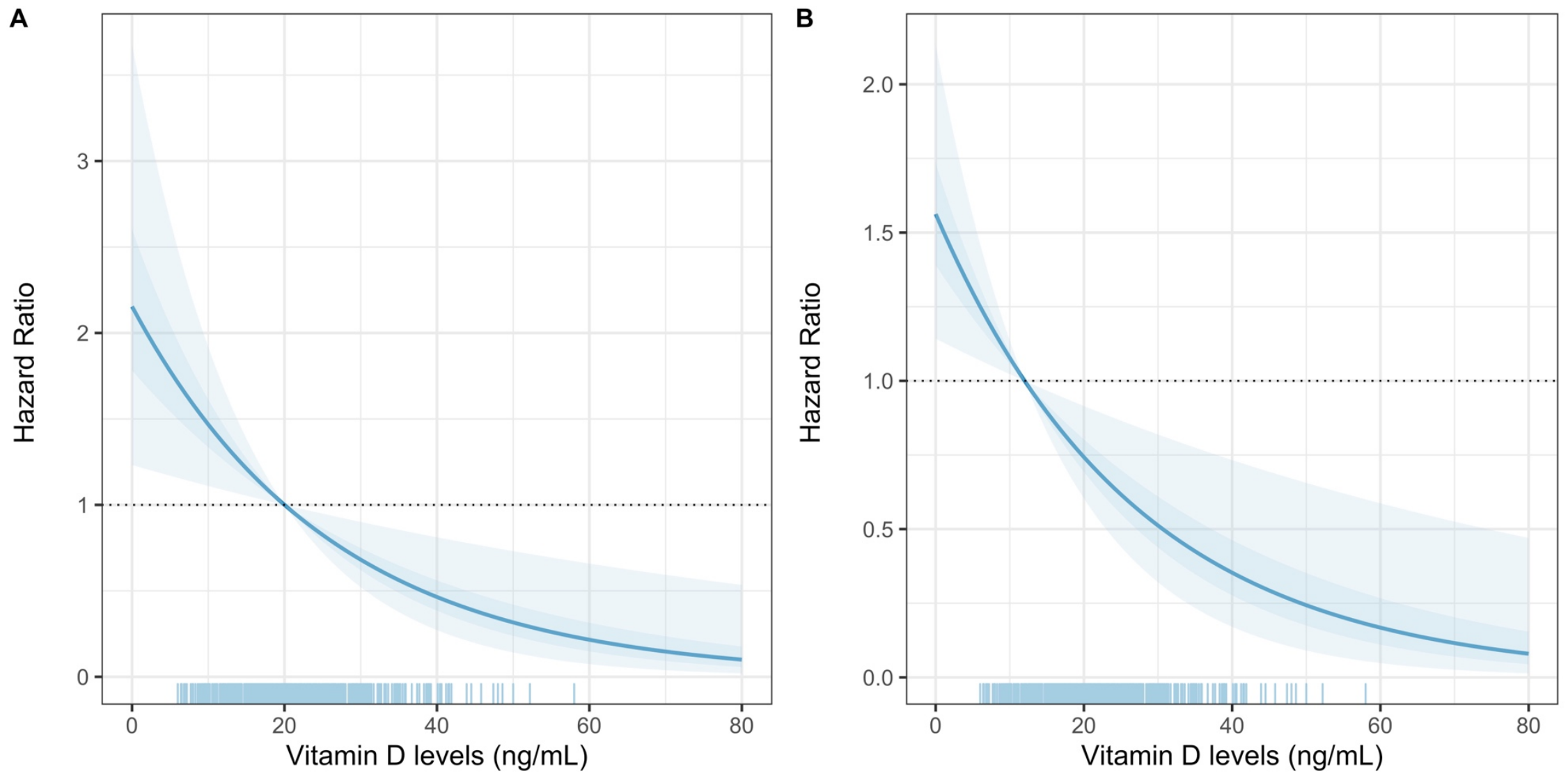

Figure 2. Post-estimation simulation of Vitamin D levels to predict COVID-19 lethality, adjusted for age, sex, BMI, C-reactive protein, epicardial fat, D-dimer, oxygen saturation, T2D, and CKD using Vitamin D cut-offs of $<20 \mathrm{ng} / \mathrm{dL}(\mathrm{A})$ and $\leq 12 \mathrm{ng} / \mathrm{mL}$ 


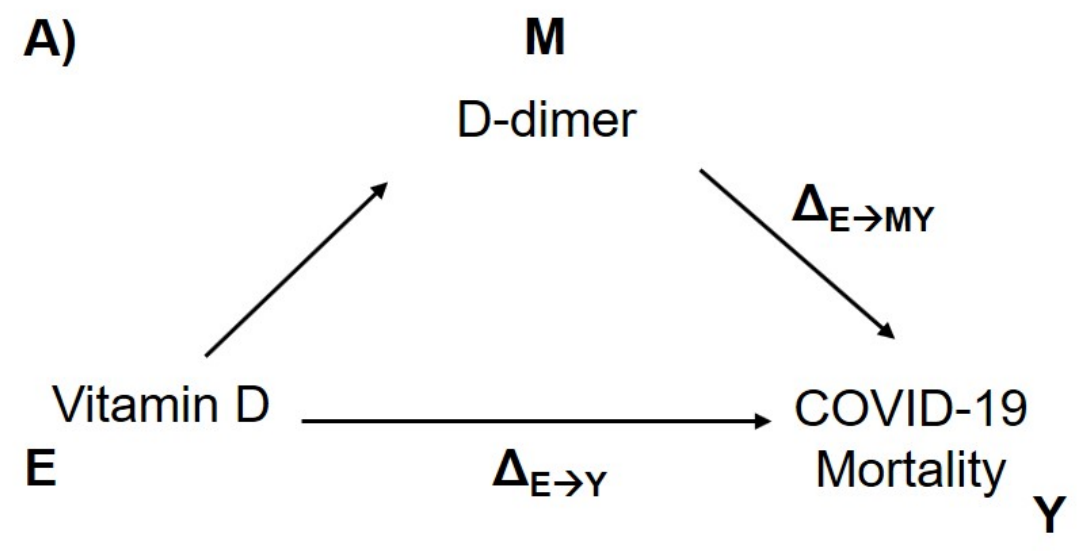

B)

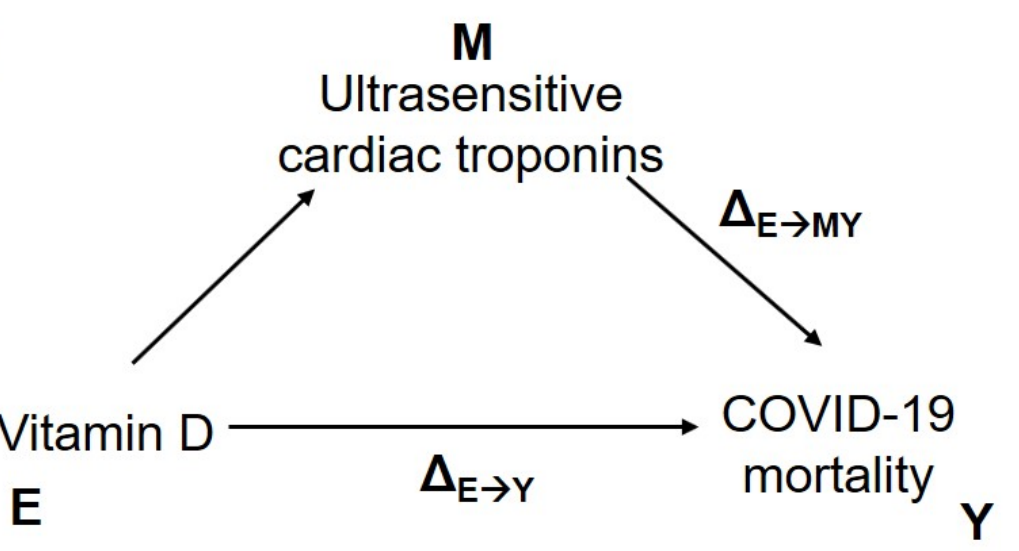

Figure 3. Model-based causal mediation analyses to investigate the role of Vitamin D on COVID-19 mortality mediated by D-dimer (A), ultrasensitive cardiac troponins $(B)$ 